Table 2. Disease activity: DAS28 score, GQL score and anxiety and depression

\begin{tabular}{|c|c|c|c|c|c|c|c|}
\hline & \multicolumn{3}{|c|}{ Anxiety } & \multicolumn{3}{|c|}{ Depression } & \multirow{3}{*}{$\begin{array}{l}\text { HADS total } \\
\text { score }(P)\end{array}$} \\
\hline & Without & With & $\mathbf{P}$ & Without & With & $\mathbf{P}$ & \\
\hline & n (\%) & n (\%) & & n (\%) & n (\%) & & \\
\hline $\begin{array}{l}\text { DAS-28 index } \\
(\mathrm{N}=48)\end{array}$ & $\begin{array}{c}31 \\
(64.4)\end{array}$ & $\begin{array}{c}17 \\
(35.4)\end{array}$ & 0.36 & $\begin{array}{c}34 \\
(70.8)\end{array}$ & $\begin{array}{c}14 \\
(29.2)\end{array}$ & 0.20 & 0.06 \\
\hline $\begin{array}{l}\text { SLEDAl index } \\
(\mathrm{N}=37)\end{array}$ & $\begin{array}{c}22 \\
(59.5)\end{array}$ & $\begin{array}{c}15 \\
(40.5)\end{array}$ & 0.79 & $\begin{array}{c}29 \\
(78.4)\end{array}$ & $\begin{array}{c}2 \\
(21.6)\end{array}$ & 0.42 & 0.05 \\
\hline $\begin{array}{l}\text { GQL index } \\
(\mathrm{N}=15)\end{array}$ & $7(46.7)$ & $\begin{array}{c}8 \\
(53.3)\end{array}$ & 0.50 & $\begin{array}{c}13 \\
(86.7)\end{array}$ & $\begin{array}{c}2 \\
(13.3)\end{array}$ & 0.25 & 0.74 \\
\hline
\end{tabular}

Disease Activity Score 28-joint counts (DAS-28) >5.1 High activity; Systemic Lupus

Erythematosus Disease Activity Index (SLEDAI) $>8$ High activity; Global Quality Index $(G Q L)>8$ high activity. HADS total score $\geq 11$.

Disclosure of Interests: None declared

DOI: 10.1136/annrheumdis-2019-eular.7952

\section{FRI0068 SAFETY OF THE ZOSTER RECOMBINANT ADJUVANTED VACCINE IN RHEUMATOID ARTHRITIS PATIENTS: A SINGLE CENTER'S EXPERIENCE WITH 300 PATIENTS}

Emma Stevens, Michael E. Weinblatt, Elena Massarotti, Frances Griffin, Sonali Desai. Brigham andWomen's Hospital, Division of Rheumatology, Immunology and Allergy, Boston, United States of America

Background: Patients with rheumatoid arthritis (RA) and other systemic rheumatic diseases (SRD) are at increased risk of developing Herpes Zoster $(\mathrm{HZ})$ due to the diseases/or medications used to treat them such as corticosteroids methotrexate, biologic disease modifying agents, and JAK inhibitors. Released in 2018, the Zoster Recombinant Adjuvanted (ZRA) is a new vaccine with $>90 \%$ efficacy and can be used in patients taking immunosuppressive therapy as compared to the live Zoster vaccine $^{1}$. There has been a concern about whether the potency of the adjuvant could trigger flares of the underlying SRD, and whether there will be more side effects in this population.

Objectives: Our goal was to study the impact of the new ZRA vaccine in RA and other SRD patients and to measure the risk of flare and incidence of side effects.

Methods: We performed a retrospective chart review from 2/1/2018 to $1 /$ 20/2019, on patients with RA and SRD seen at the BWH who had received the ZRA vaccine. Co-variates of interest were collected. A flare was defined as occurring within 12 weeks of the vaccine administration by either: 1) documentation of RA flare in the rheumatologist office notes, telephone encounter or patient portal communication, or 2) new prednisone prescription or an increase in dose of existing prednisone prescription. Vaccine side effects were defined as muscle soreness at the injection site, redness, mild swelling, fatigue, fevers, myalgias, headaches, nausea, and abdominal pain.

Results: 300 patients who received the new ZRA vaccine between 2/1/ 2018 to $1 / 20 / 2019$ were identified. Mean follow up was 12.5 weeks ranging from 1-40 weeks following administration. Patient characteristics are identified in Table 1.

We identified a $3.00 \%(n=9)$ incidence of flare following the first dose and $2.86 \%(n=4)$ incidence following the second dose. One patient flared after both the first and second dose. All the flares were mild, self-limited, responded to treatment with low dose glucocorticoids, and did not warrant a change in immunosuppressive therapy. $15.3 \% \quad(n=46)$ patients experienced side effects such as soreness at the injection site, fever, stomach ache, and flu like symptoms. Of the patients who experienced side effects, $15.4 \% \quad(n=40)$ occurred after the first dose and $8.59 \% \quad(n=11)$ occurred following the second dose. Five patients experienced side effects from both. All side effects were regarded as mild and did not necessitate an emergency room visit. No cases of Zoster were reported.

\begin{tabular}{lc}
\hline Total N & 300 \\
\hline Mean Age & $67.5( \pm 11.1)$ \\
Females & $232(77.3 \%)$ \\
Seropositive & $111(53.6 \%)$ \\
Received 2nd Vaccine & $140(46.7 \%)$ \\
Medications & \\
MTX (mean dose=17.1mg/week) & $118(39.3 \%)$ \\
Prednisone (mean dose=4.69 mg/day) & $81(27.0 \%)$ \\
Tofacitinib & $44(14.7 \%)$
\end{tabular}

TNF inhibitors *

$91(30.3 \%)$

Other biologic therapy ** $47(15.7 \%)$

Other immunosuppressants ${ }^{\star * *}$

Diagnosis

RA

Psoriatic Arthritis

$207(69.0 \%)$

$21(7.00 \%)$

Psculitis

$12(4.00 \%)$

SLE

$11(3.67 \%)$

CTD/MCTD

$7(2.33 \%)$

Other ${ }^{* * * *}$

$42(14.0 \%)$

${ }^{*}$ Adalimumab, Certolizumab pegol, Etanercept, Golimumab, Infliximab

** Abatacept, Tocilizumab, Rituximab, Sarilumab

${ }^{* *}$ Azathioprine, Cyclophosphamide, Mycophenolic acid, Leflunomide

${ }^{\star * \star *}$ Other includes: Gout, Scleroderma, Sjogren's, Ankylosing spondylitis, Dermatomyositis

Conclusion: In our experience with 300 patients who received the new ZRA (207 RA and 93 SRD) in 2018-2019, the incidence of disease flares was $\leq 3 \%$ and of side effects was $15 \%$ which is reassuring. Both flares and side effects were mild, self-limited, and did not require a change in DMARD therapy. No cases of Zoster were reported. Larger formal studies with longer term follow up are required to confirm our findings.

\section{REFERENCE:}

[1] Shingrix Recommendations.cdc.gov. https://www.cdc.gov/vaccines/vpd/ shingles/hcp/shingrix/recommendations.html

Disclosure of Interests: Emma Stevens: None declared, Michael E. Weinblatt Shareholder of: Stock option: CanFite, Lycera, Scipher, Inmedix Grant/research support from: Crescendo Bioscience, Bristol Myers Squibb, Sanofi, Consultant for: AbbVie, Amgen, Bristol-Myers Squibb, CanFite Corrona, Crescendo, GlaxoSmithKline, Gilead, Horizon, Lilly, Lycera Merck, Novartis, Pfizer, Roche, Samsung, Scipher, Set Point, Elena Massarotti : None declared, Frances Griffin: None declared, Sonali Desai None declared

DOI: 10.1136/annrheumdis-2019-eular.4337

\section{FRI0069 FREQUENCY OF EYE INVOLVEMENT IN INFLAMMATORY ARTHRITIS AND CONNECTIVE TISSUE DISEASE: A SYSTEMATIC REVIEW AND META- ANALYSIS}

Matthew Turk ${ }^{1}$, Jacqueline Hayworth ${ }^{2}$, Tatiana Nevskaya ${ }^{1}$, Janet Pope ${ }^{1}$. ${ }^{1}$ university of western ontario, London, Canada; ${ }^{2}$ university of toronto, toronto, Canada

Background: Rheumatoid arthritis commonly presents with extraarticular manifestations. Along with other connective tissue diseases, these manifestations may include eye involvement.

Objectives: The purpose of our work was to determine the prevalence and type of eye involvement in rheumatoid arthritis and other connective tissue diseases through a meta-analysis and literature review.

Methods: A systematic review of the literature was performed using Medline, Web of Science, and the Cochrane library from their inceptions until January 7, 2019. Conjunctivitis, keratoconjunctivitis sicca, xeropthalmia, uveitis, eye hemorrhage, optic neuritis, papilledema, orbital disease, retinal artery/vein occlusion, macular edema, retinitis, chorioretinitis, scleritis, iridocyclitits, choroid hemorrhage, blindness and amaurosis fugax were searched for prevalence in patients with rheumatoid arthritis, systemic lupus erythematosus, antiphospholipid syndrome, dermatomyositis, polymyositis, systemic sclerosis, Sjogren's syndrome, undifferentiated connective tissue disease, giant cell arteritis, granulomatosis polyangiitis (GPA; formerly Wegener's granulomatosis, systemic vasculitis, and sarcoidosis.

Results: 3394 studies were identified and 65 included. The prevalence of eye involvement was $18 \%$ in rheumatoid arthritis, $31 \%$ in systemic lupus erythematosus, $35 \%$ in antiphospholipid syndrome, $27 \%$ in giant cell arteritis, $26 \%$ in GPA and $27 \%$ in sarcoidosis. The most common manifestations was dry eyes (keratoconjunctivitis sicca) in most diseases analyzed with a frequency approaching $90 \%$ in Sjogren's syndrome. Anterior and posterior uveitis were the most common OC in sarcoidosis occurring in $16[3-28] \%$ and $6[3-9] \%$ of patients respectively.

Conclusion: Eye involvement is present in approximately one fifth of rheumatoid arthritis patients, and one quarter to one third of patients with other rheumatic diseases. 


\section{REFERENCES:}

[1] Grassi W, De Angelis R, Lamanna G, Cervini C. The clinical features of rheumatoid arthritis. Eur J Radiol 1998;27 Suppl 1:S18-24.

[2] Brito-Zerón P, Acar-Denizli N, Zeher M, Rasmussen A, Seror R, Theander $E$, et al. Influence of geolocation and ethnicity on the phenotypic expression of primary Sjögren's syndrome at diagnosis in 8310 patients: a crosssectional study from the Big Data Sjögren Project Consortium. Ann Rheum Dis 2017;76:1042-50.

[3] Zhang C, Zha Q-L, He Y-T, Jiang M, Lü C, Lü A-P. The extraarticular symptoms influence ACR response in the treatment of rheumatoid arthritis with biomedicine: a single-blind, randomized, controlled, multicenter trial in 194 patients. J Tradit Chin Med 2011;31:50-5.

[4] Kermani TA, Cuthbertson D, Carette S, Hoffman GS, Khalidi NA, Koening $\mathrm{CL}$, et al. The Birmingham Vasculitis Activity Score as a Measure of Disease Activity in Patients with Giant Cell Arteritis. The Journal of Rheumatology 2016;43:1078-84.

[5] Seror R, Theander E, Brun JG, Ramos-Casals M, Valim V, Dörner T, et al. Validation of EULAR primary Sjögren's syndrome disease activity (ESSDAI) and patient indexes (ESSPRI). Ann Rheum Dis 2015;74:859-66.

[6] Valeyre D, Prasse A, Nunes H, Uzunhan Y, Brillet P-Y, Müller-Quernheim J. Sarcoidosis. Lancet 2014;383:1155-67.

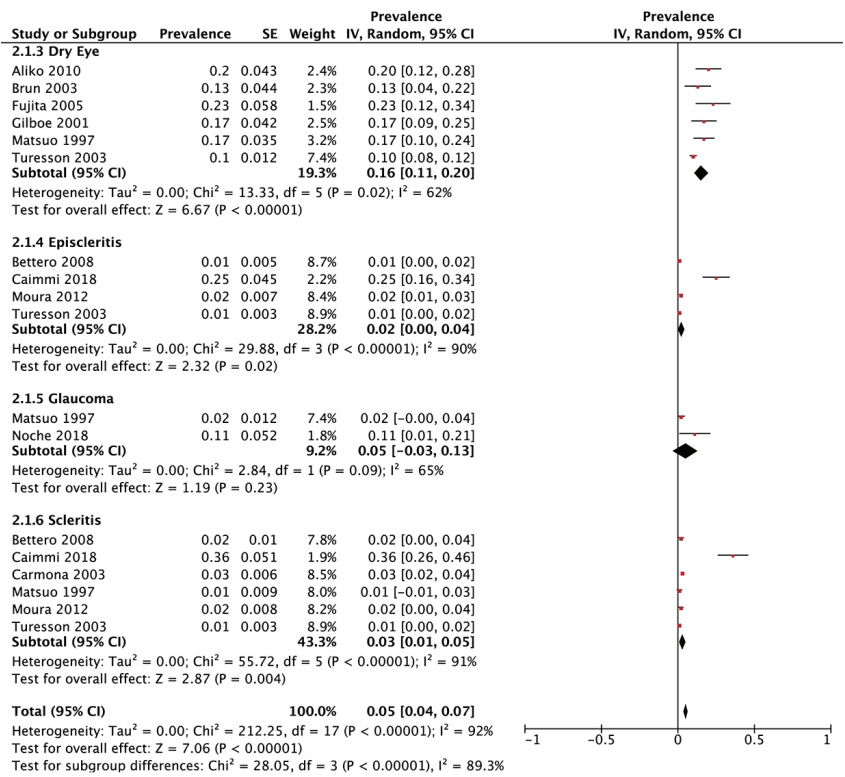

Figure 4. the frequency of different ocular manifestations in RA. A) Dry Eye, B) Episcleritis, C) Glaucoma, D) scleritis

Disclosure of Interests: Matthew Turk: None declared, Jacqueline Hayworth: None declared, Tatiana Nevskaya: None declared, Janet Pope Consultant for: Eli Lilly and Company

DOI: 10.1136/annrheumdis-2019-eular.6170

\section{FRI0070 SHORT-TERM INFLAMMATORY AND LIPIDS CHANGES IN RHEUMATOID ARTHRITIS PATIENTSINFLUENCE CARDIOVASCULAR RISK ALGORITHMS: A MONOCENTRIC RETROSPECTIVE STUDY}

vincenzo venerito, Marco Fornaro, Giuseppe Lopalco, Anna Abbruzzese, Sergio Colella, Maria Grazia Anelli, Giovanni Lapadula, Florenzo lannone, Fabio Cacciapaglia. Policlinico of Bari, Rheumatology Unit, Department of Emergency and Organ Transplantations, Bari, Italy

Background: Chronic inflammation may change lipid profile, thus current EULAR recommendations for cardiovascular (CV) management in polyarthritis suggest to assess cholesterol status when disease activity is stable or in remission ${ }^{1}$. To date it is still unclear whether inflammation mediated changes in lipids profile could impact on CV risk algorithms and what score should be considered the reference one for any disease activity status.
Objectives: The aim of this study was to evaluate the influence of lipid profile, disease activity and inflammation modifications on four CV risk calculators during Treat to Target strategy with biologic agents.

Methods: In this monocentric study we retrospectively evaluated all data recorded from Rheumatoid Arthritis (RA) patients with moderate/high CDAI disease activity, who had started for the first time and maintained a bDMARD agent for at least 6 months, in our Outpatient Clinic from the $1^{\text {st }}$ January 2010 to $31^{\text {st }}$ December 2017. Patients with a prior CV event have been excluded from the analysis. For each patient, we assessed the $\mathrm{CV}$ risk in a short time period (within 6 months) to estimate the specific weight of lipids and disease activity related variables, using the Italian CV "Progetto Cuore" score ${ }^{2}$, the QRISK3-2018 score ${ }^{3}$, the Reynolds Risk Score $(R R S)^{4}$ and the Expanded Risk Score in RA (ERS-RA) ${ }^{5}$. The results of the "Progetto CUORE" and RRS algorithms were multiplied by 1.5, in accordance to the EULAR recommendations for algorithms that do not include specifically RA among variables. Wilcoxon signed-rank test was used to compare CV risk scores during follow-up.

Results: One-hundred thirteen RA patients (female n. 86 (76.8\%), mean age (SD) 52.8 (12.9) years, median disease duration (IQR) 26 (13-72) months) were eligible for the analysis. CDAI and C-reactive protein levels decreased significantly either at 3 and 6 months follow-up $(p<0.001)$. At 3 months, we observed a statistically significant increase in mean total cholesterol (TC) from $197.3 \pm 38.2 \mathrm{mg} / \mathrm{dl}$ to $205.8 \pm 37.3 \mathrm{mg} / \mathrm{dl} \quad(p<0.01)$, which returned close to baseline levels at 6 months $(201.1 \pm 34.5 \mathrm{mg} / \mathrm{dl}$ $\mathrm{p}=0.22$ vs baseline). High density lipoprotein (HDL), TC/HDL ratio and triglycerides changes did not reach the statistically significance. The estimated CV risk assessed by the "Progetto Cuore" and QRisk3-2018 did not change during the 6 months' follow-up. RRS showed a decrease either at 3 and 6 months $(p=0.04)$. Similarly, ESR-RA highlighted a decrease of $C V$ risk either at 3 and 6 months $(p<0.01)$ (see Table I). Conclusion: All evaluated "Scores" are not influenced by short term lipid changes observed during bDMARDs treatment, being applicable at any status of disease activity. Interestingly, the RRS and ESR-RA scores, evaluating RA inflammatory items, are susceptible to disease activity changes. These results should be taken into account by rheumatologists choosing a CV risk algorithm in daily clinical practice.

\begin{tabular}{|c|c|c|c|}
\hline & Esseline & 3-month follow up & 6-month followup \\
\hline$C B P$ & $72(5: 26)$ & $3(267.6) *$ & $39(2465) *$ \\
\hline COAN & is (8:-23) & $6(2 \cdot 12) * *$ & $4(2, x)$ \\
\hline IC (so) & $197.3(28.2)$ & $\cos 8(37,3) *$ & mas(s) \\
\hline not (so) & $\cos 1: 69$ & 6291259 & $6: 2$ (135) \\
\hline IC/HOL ratio (SO) & $34(21)$ & $3(095)$ & $34(09)$ \\
\hline Trigiverides (so) & $1223(782)$ & $210: 160.5)$ & :ces (ss:) \\
\hline "Progetto cuore" & $28(0.7 .75)$ & $28(0,7.81)$ & $26(0.7 .78)$ \\
\hline QRisk3-2018 & $38(24: 49)$ & $26(2.2-142)$ & $2 A(23: 46)$ \\
\hline ERS-RA & $63(32.452)$ & $6.4(28: 13) \cdot V$ & s:0(2:-2s) * \\
\hline RES & $20(25325)$ & $30(15,5)^{\circ}$ & $30125.25)^{\circ}$ \\
\hline
\end{tabular}

Values expressed as median (1OR). SO: standard deviation. CRP: C-restive protein. COA: Clinical Oisesse Activity Index. IC: Total-cholesterol. HOt: high density lipoprotein. ERS-RA: Expanded Risk Score in Rheumatoid Authritis, RRS Reynolds Risk score.

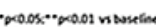

\section{REFERENCES:}

[1] Agca R, et al. Ann Rheum Dis 2017;76:17-28

[2] Palmieri L, et al. Ann Ist Super Sanita. 2004;40(4):393-9.

[3] Hippisley-Cox J, et al. BMJ. 2017 May 23;357:j2099.

[4] Ridker PM, et al. JAMA. 2007;297(6):611-9.

[5] Solomon DH, et al. Arthritis Rheumatol. 2015;67(8):1995-2003.

Disclosure of Interests: vincenzo venerito: None declared, Marco Fornaro: None declared, Giuseppe Lopalco Speakers bureau: SOBI, BMS, Anna Abbruzzese: None declared, Sergio Colella: None declared, Maria Grazia Anelli: None declared, Giovanni Lapadula: None declared, Florenzo lannone Consultant for: $F$ lannone has received consultancy fees and/or speaker honoraria from Pfizer, AbbVie, MSD, BMS, Novartis, Lilly, UCB outside this work, Speakers bureau: $F$ lannone has received consultancy fees and/or speaker honoraria from Pfizer, AbbVie, MSD, BMS, Novartis, Lilly, UCB outside this work, Fabio Cacciapaglia: None declared DOI: 10.1136/annrheumdis-2019-eular.7529 